\title{
Transluminal Route of Administration
}

National Cancer Institute

\section{Source}

National Cancer Institute. Transluminal Route of Administration. NCI Thesaurus. Code C38306.

The route of drug administration involving the passage of an inflatable catheter along the lumen of a blood vessel. 